\title{
Study of the viscosity and thermal characteristics of polyolefins/solvent mixtures: applications for plastic pyrolysis
}

Ali Zolghadr*, Azarnoosh Foroozandehfar, Daniel G. Kulas, David Shonnard,

Department of Chemical Engineering, Michigan Technological University, 1400 Townsend Dr,

Houghton, MI.

*Corresponding Author 
Figure S-1 shows the dynamic viscosity chart of LDPE/solvent mixtures at various LDPE percentages, RPMs, and temperatures. Since the viscosity of the LDPE/solvent mixtures was low, especially at high temperatures and with a low LDPE percentage and low RPMs (e.g., LDPE 50\% at a temperature above $140^{\circ} \mathrm{C}$ ), the viscosity was not measurable at low RPMs with the viscometer used in this study. For most of the dynamic-viscosity results, the viscosity of the LDPE/solvent was roughly constant with the increasing RPMs. This might indicate Newtonian fluid behavior of our LDPE/solvent mixtures.
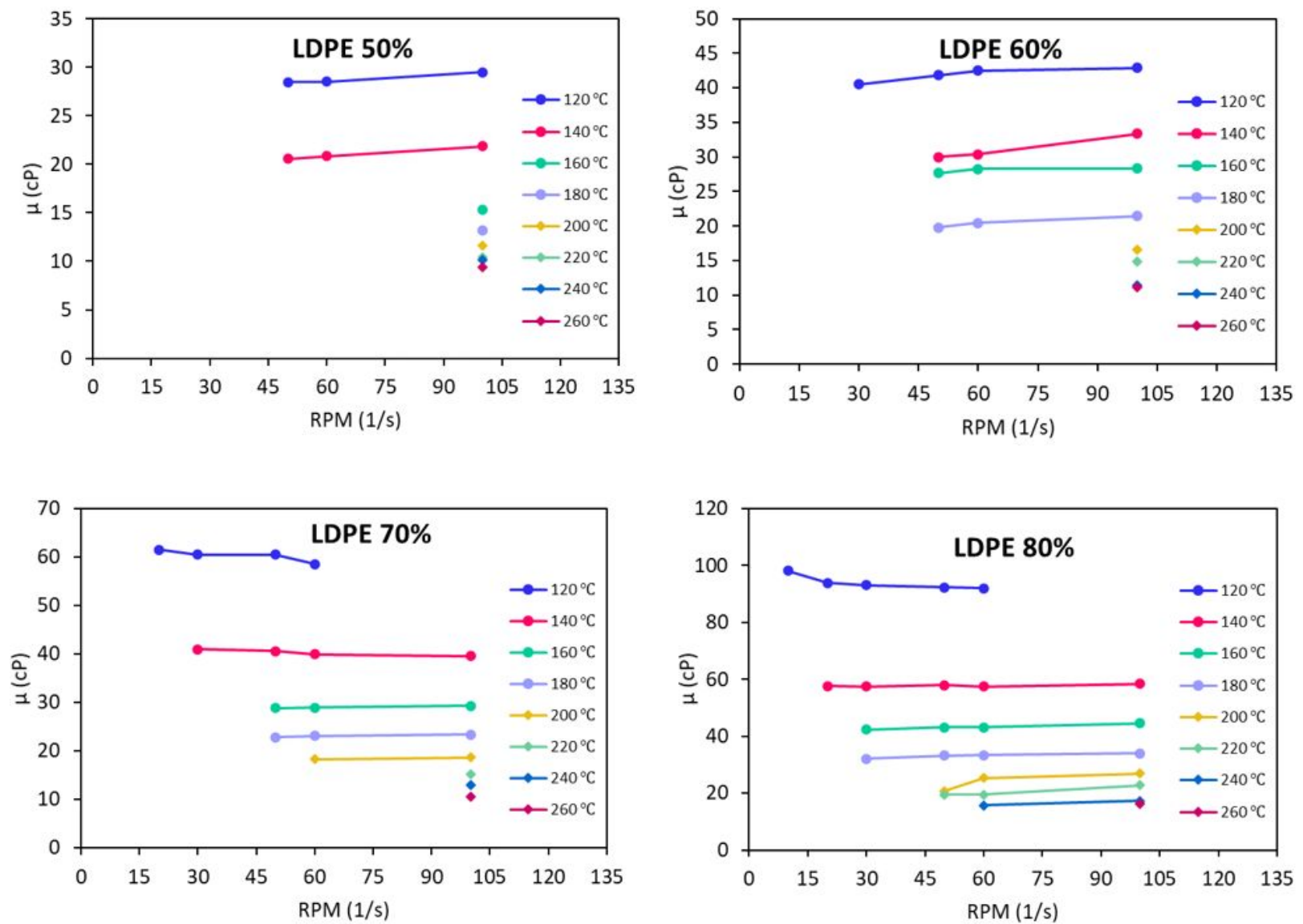

Figure S-1. Dynamic viscosity of LDPE/solvent mixture at different temperatures. 
The dynamic viscosity of HDPE/solvent mixtures is shown in Figure S-2. As the results illustrated, the viscosity of HDPE was four orders of magnitude higher than LDPE since the molecular weight of the HDPE was higher than LDPE (more details are described in the manuscript). For the HDPE $30 \%$ wt at $160^{\circ} \mathrm{C}$ and HDPE $50 \%$ wt at $200^{\circ} \mathrm{C}$ and $220^{\circ} \mathrm{C}$, the viscosity was decreased as the RPMs increased (this might be due to shear-thinning fluid behavior). However, the viscosity vs. RPMs was roughly constant at higher temperatures in both mixtures. For the HDPE 50\% wt, the range of RPMs was limited (the viscosity was not measurable at high RPMs due to an apparatus limitation on allowable torque). Thus, the trend of the viscosity vs. RPM was not determinable. A huge drop in viscosity was observed at high temperatures (e.g. HDPE $50 \%$ at $240^{\circ} \mathrm{C}$ ). Gas bubbles (Figure S-5) also appeared at those temperatures. Even though the appearance of gas bubbles in the system always includes a huge viscosity reduction, it is difficult to distinguish between the effects of gas bubbles and temperature on viscosity reduction.
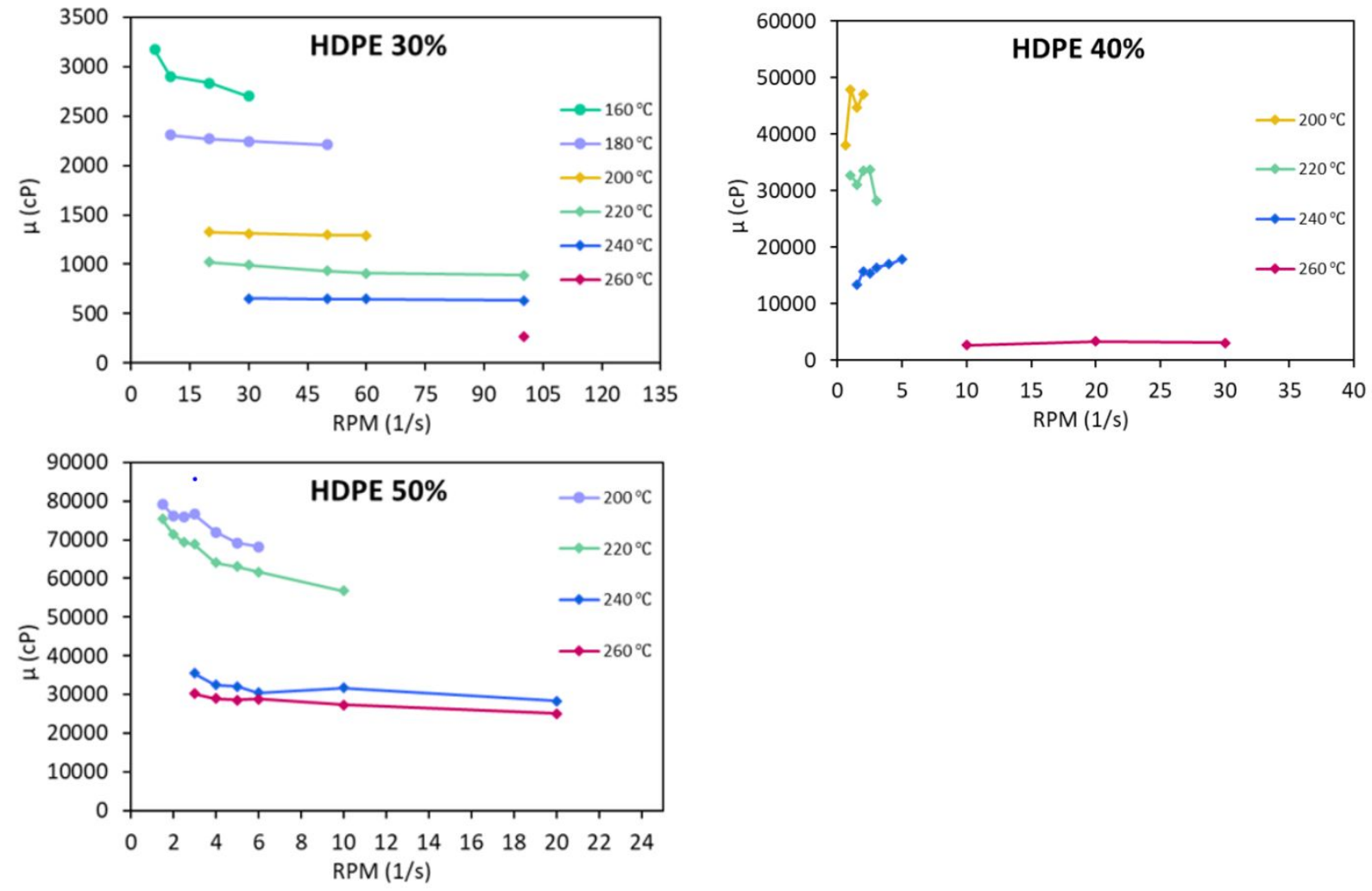
Figure S-2. Dynamic viscosity of HDPE/solvent mixture at different temperatures.

Figure S-3 shows the dynamic viscosity of $\mathrm{PP}_{\mathrm{S}} /$ solvent mixtures at various $\mathrm{PP}_{\mathrm{S}}$ percentages. This is similar to LDPE/solvent mixtures. Since the viscosity was low at low $\mathrm{PP}_{\mathrm{S}}$ percentages $\left(\mathrm{PP}_{\mathrm{S}} 30 \%\right.$ and $50 \% \mathrm{wt}$ ), the viscosity was not measurable (apparatus limitation) at low RPMs. For PP $70 \%$, the viscosity v. RPM was roughly constant, and the fluid might be a Newtonian fluid. No gas bubbles were observed in $\mathrm{PP}_{\mathrm{S}} /$ solvent mixtures or LDPE/solvent mixtures; however, they were observed for $\mathrm{HDPE} /$ solvent mixtures and $\mathrm{PP}_{\mathrm{P}} /$ solvent mixtures at high temperatures. An explanatory hypothesis is that the solvent cannot evaporate from the high viscosity mixture (HDPE/solvent mixtures and $\mathrm{PP}_{\mathrm{P}} /$ solvent mixtures) as well as it can from low viscosity mixtures (LDPE/solvent mixtures and $\mathrm{PP}_{\mathrm{S}} /$ solvent mixtures).
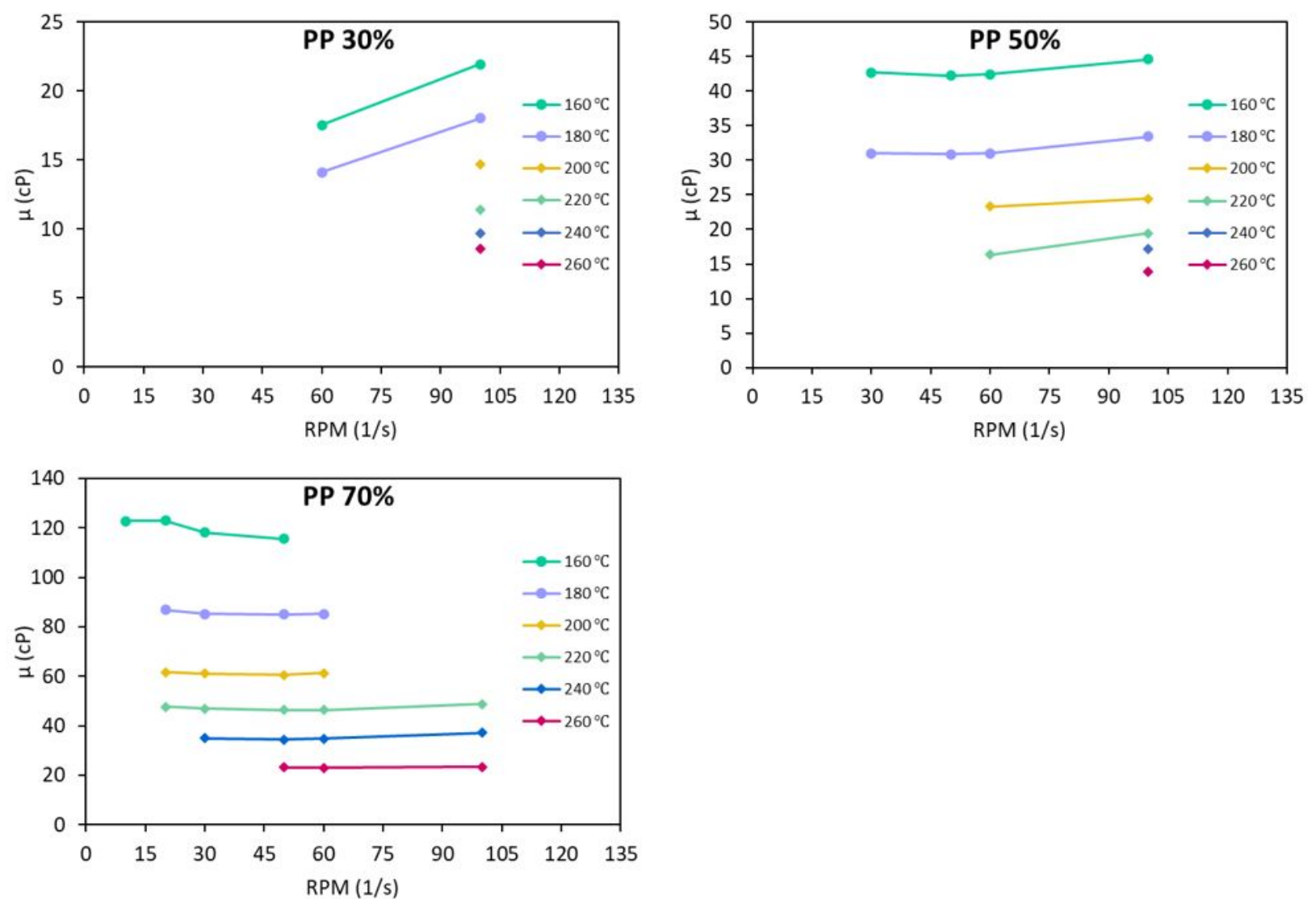
Figure S-3. Dynamic viscosity of $\mathrm{PP}_{\mathrm{S}}$ /solvent mixture at different temperatures.

Figure S-4 shows the dynamic viscosity of $\mathrm{PP}_{\mathrm{p}} /$ solvent mixtures at various $\mathrm{PP}_{\mathrm{P}}$ percentages and temperatures. The viscosity of the $\mathrm{PP}_{\mathrm{p}} 30 \% \mathrm{wt}$ at a temperature of $200^{\circ} \mathrm{C}$ had a huge drop in comparison to a temperature of $160^{\circ} \mathrm{C}$. At the same temperature $\left(200^{\circ} \mathrm{C}\right)$, gas bubbles appear in the mixtures. Similar to HDPE, the viscosity reduction in the mixture could be due to the appearance of gas bubbles or/and an increase in temperature. A similar trend was observed for PPp $50 \%$, but the viscosity reduction and appearance of bubbles started at $220^{\circ} \mathrm{C}$ instead of at $180^{\circ} \mathrm{C}$. For PPp $40 \%$, the bubbles appear at $200^{\circ} \mathrm{C}$. For all the viscosity results reported in the main manuscript, the lowest RPM (shear rate) was selected.
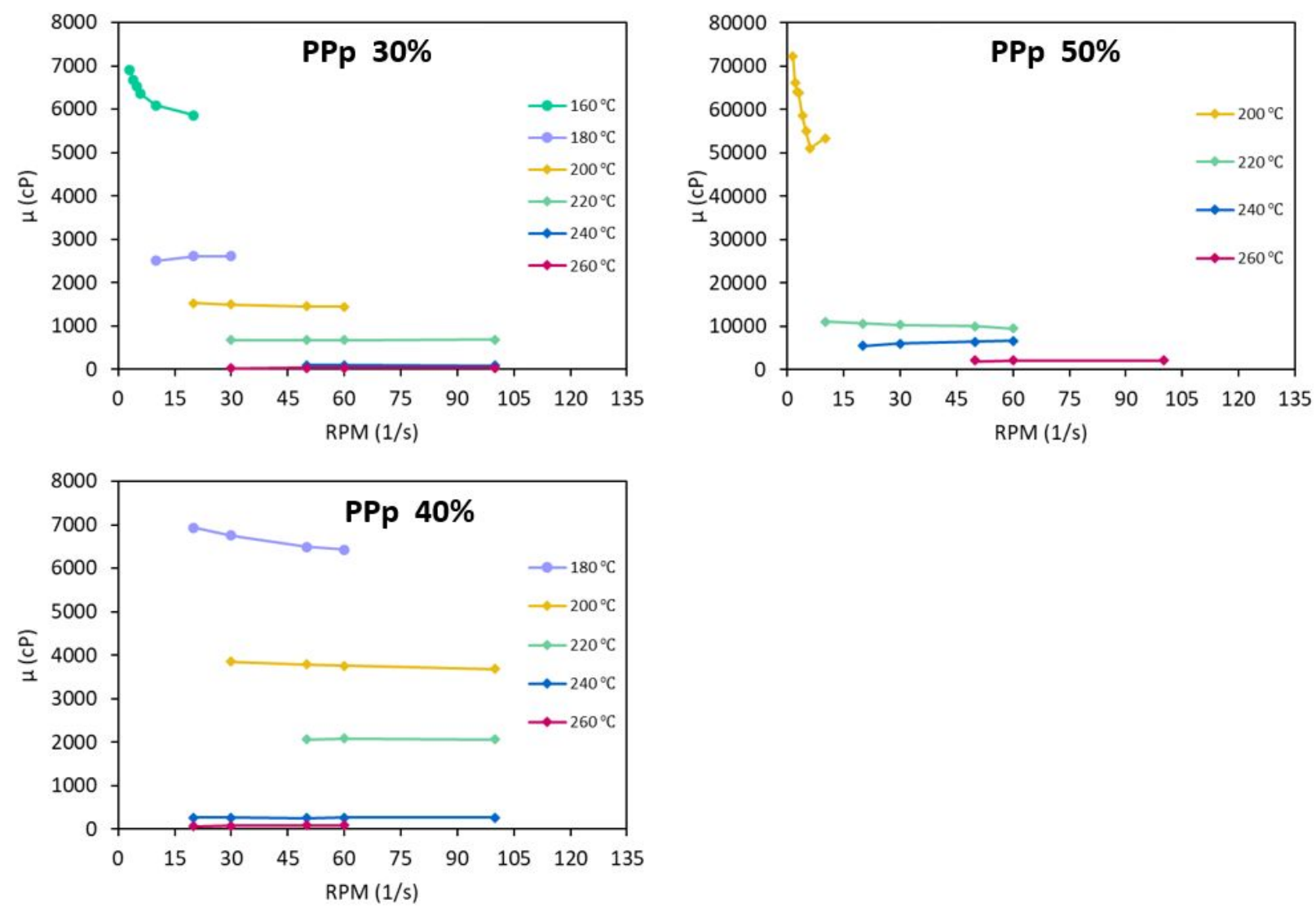

Figure S-4. Dynamic viscosity of $\mathrm{PP}_{\mathrm{P}} /$ solvent mixture at different temperatures. 
Figure S-5 shows the appearance of gas bubbles in the HDPE/solvent mixtures at $240^{\circ} \mathrm{C}$. One of the hypotheses regarding the appearance of gas bubbles in a high-temperature and high-viscosity mixture is that the solvent vapors cannot evaporate from the mixture fast enough and bubbles form.

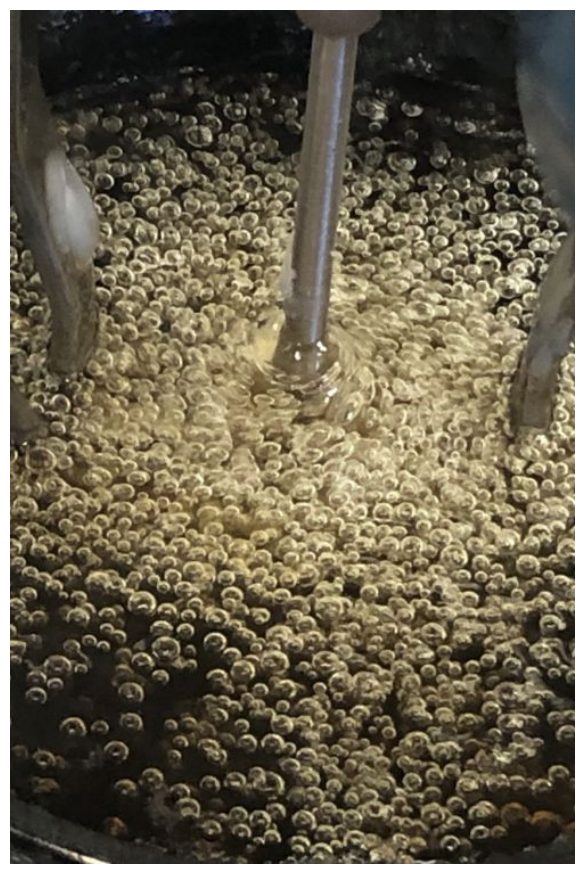

Figure S-5. Gas bubbles in the $50 \mathrm{wt} \% \mathrm{HDPE} /$ solvent mixture. Photograph courtesy of Ali Zolghadr. Reprinted, adapted or reprinted in part with permission from Ali Zolghadr, Zolghadr.a@gmail.com. Copyright [2021/Ali Zolghadr] [ASC Omega Journal/Ali Zolghadr]. 
Figures S-6 and S-7 show the repeatability of the DSC data. The average standard deviation for the heat flow curve of $25 \%$ PPs was $0.19 \mathrm{~mW}$, and $75 \%$ PPs was $0.33 \mathrm{~mW}$, indicating good reproducibility of the results.

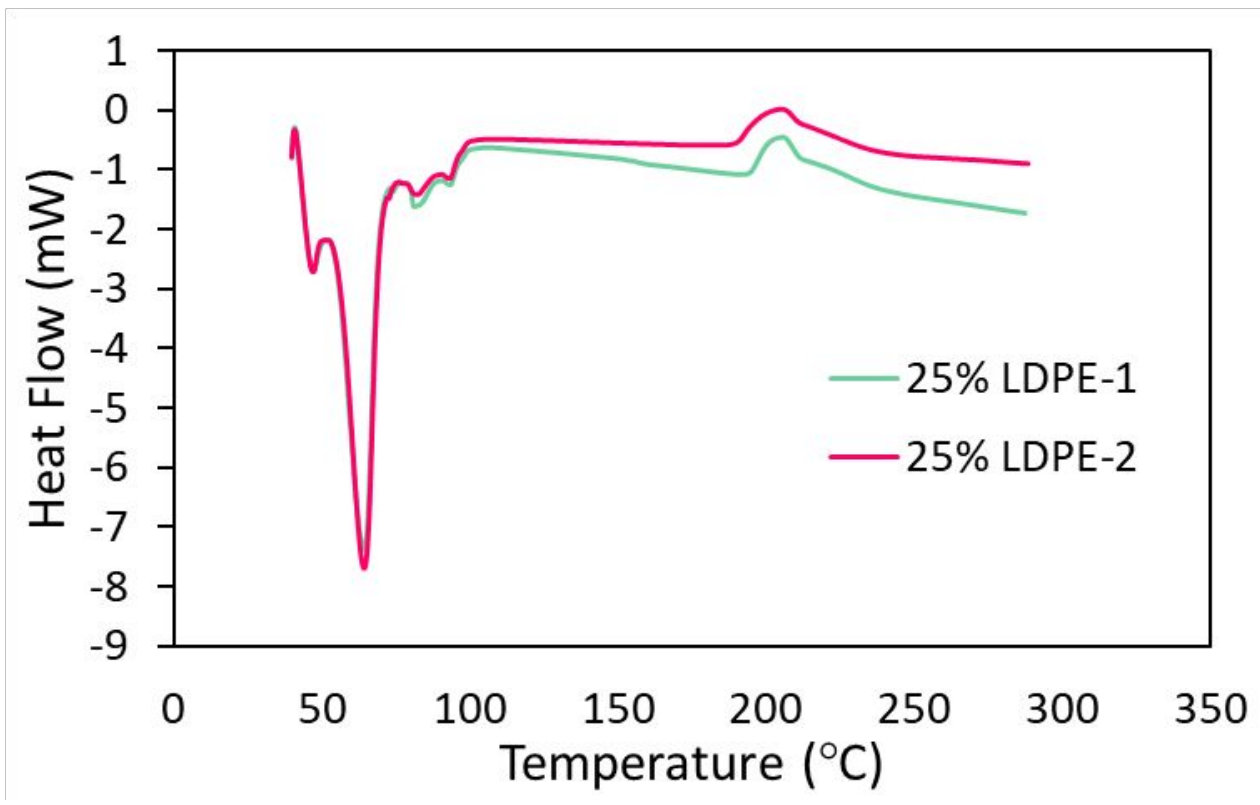

Figure S-6. The reproducibility of the DSC results for the 25\%LDPE/ $75 \%$ solvent mixture.

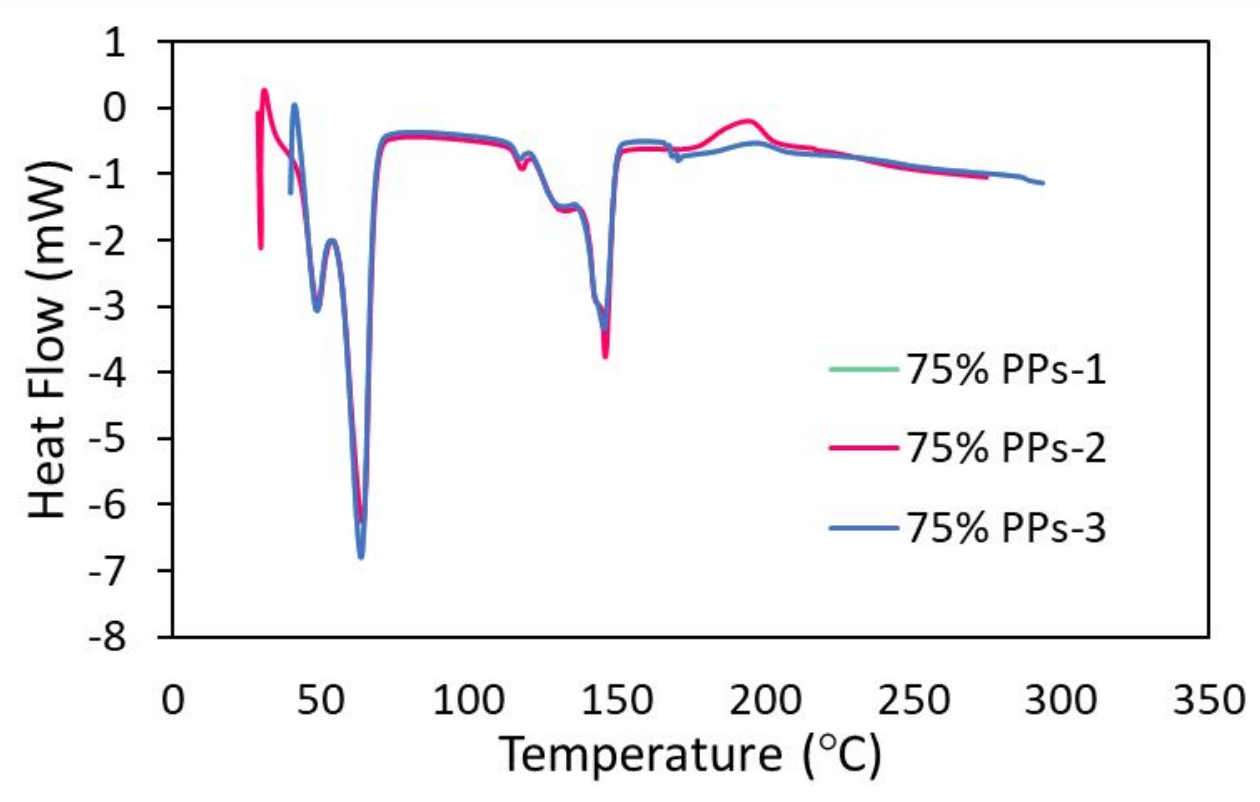


Figure S-7. The reproducibility of the DSC results for the $75 \% \mathrm{PPs} / 25 \%$ solvent mixture.

Figures S-8, S-9, S-10, and S-11 demonstrate the repeatability of the DTG data. The average standard deviation for the deriv. weight change of 100\% HDPE, 100\% LDPE, 100\% PPP, and $100 \%$ PPS was $0.005,0.078,0.005$, and $0.063 \% /{ }^{\circ} \mathrm{C}$, respectively. This indicates great reproducibly for DTG results.

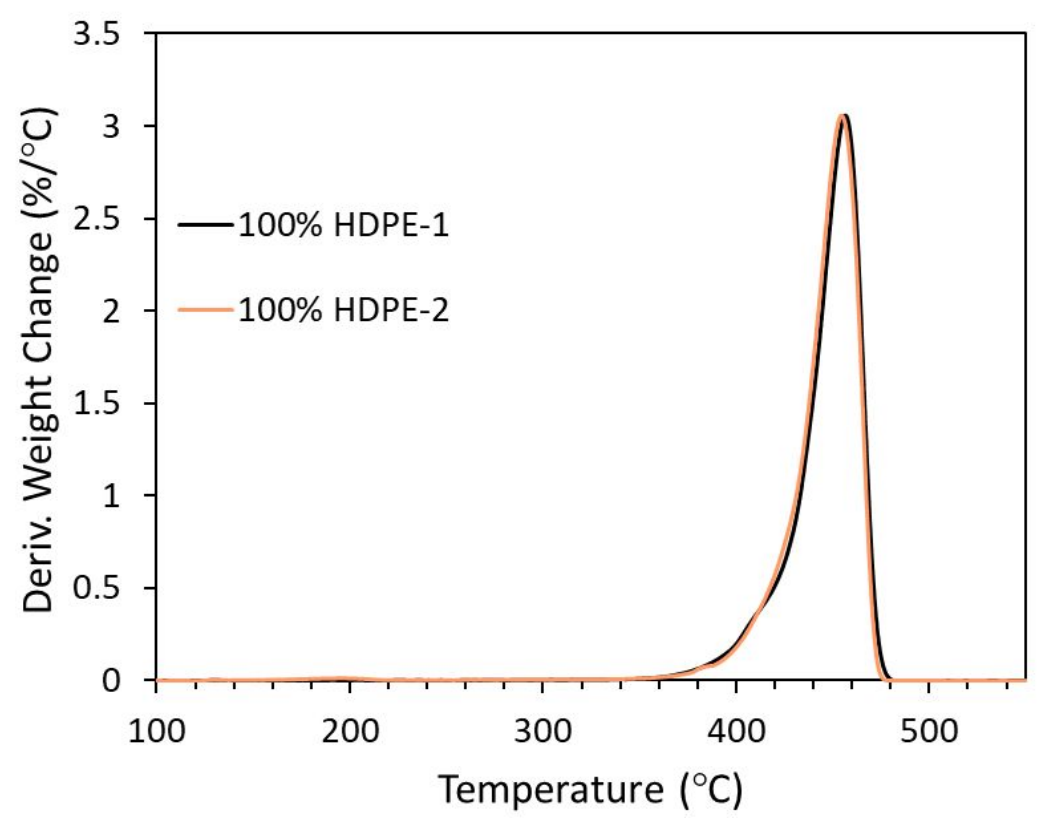

Figure S-8. The reproducibility of the DTG results for the pure HDPE. 


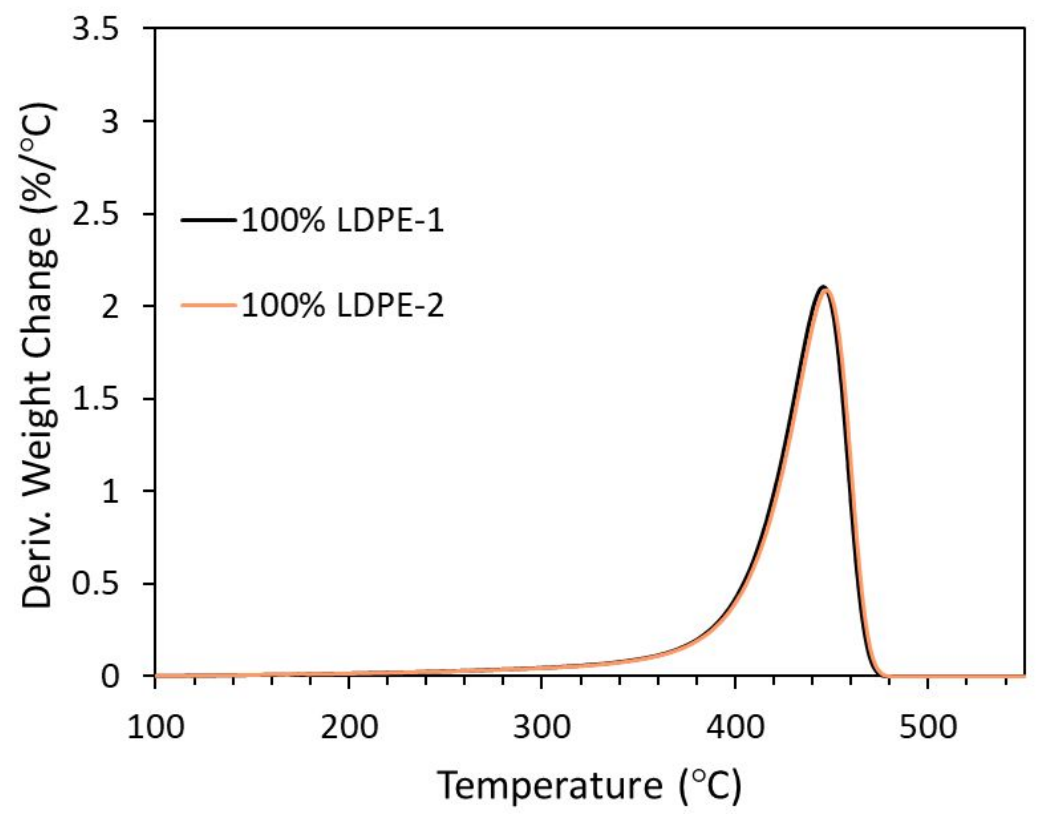

Figure S-9. The reproducibility of the DTG results for the pure LDPE.

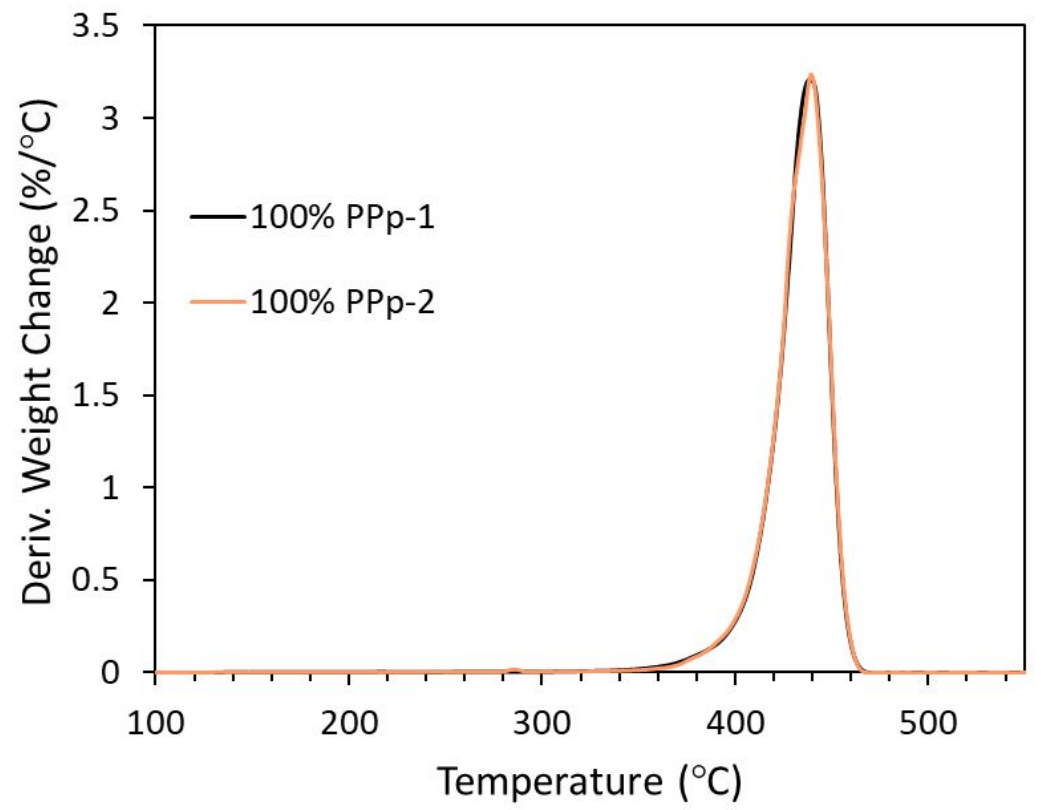

Figure S-10. The reproducibility of the DTG results for the pure PPp. 


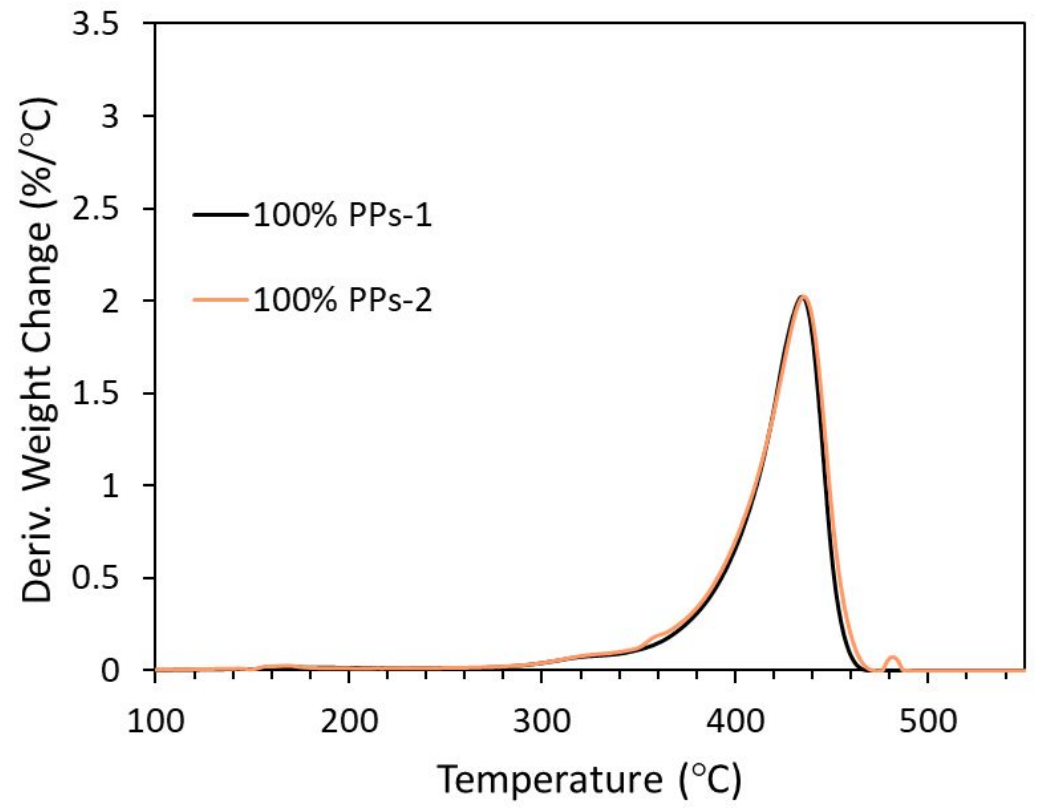

Figure S-11. The reproducibility of the DTG results for the pure PPs. 